2020, Volume 14, International Conference Innovative Business Management \& Global Entrepreneurship (IBMAGE 2020), pages: 205-211 |

https://doi.org/10.18662/lumproc/ibmage2020/15

\section{Fintech as a Mean for Digital and Financial Inclusion}

\section{Heike BÄHRE1, Giovanni BUONO2, Valerie Isabel ELSS3*}

${ }^{1}$ Fachhochschule des Mittelstands, Bielefeld, Germany, baehre@,fhmittelstand.de

${ }^{2}$ LUMSA University, Rome, Italy, giovanni@,fintechedulab.com

${ }^{3}$ Fachhochschule des Mittelstands, Bielefeld, Germany, elss@ffh-mittelstand.de Corresponding author
Abstract: Finance is shaping human relationship from an economic point of view as well as having influences on social structure and politics. In this relation, Fintech, a combination of the words "Finance" and "Technology", is defined as "a new financial industry that applies technology to improve financial activities" [11] or as those "applications, processes, products, or business models in the financial services industry, composed of one or more complementary financial services and provided as an end-to-end process via the Internet" [10] or as "any innovative ideas that improve financial service processes by proposing technology solutions according to different business situations, while the ideas could also lead to new business models or even new businesses" [8]. As Bill Gates said "Banking is necessary; banks are not" describing what is happening throughout the financial industry: massive disappearing of traditional jobs, consolidation in the banking industries, robots that advice how to manage and save money. These changes have an impact on the social structure, but also have the potential to systematically promote financial literacy and inclusion. For example Grohmann, Klühs and Menkhoff [7] showed across four indicators of financial inclusion (having a bank account, having a debit card, saving in form of a bank account and the use of the debit card within the last year) that financial literacy is a significant precondition for financial inclusion. To what extent can Fintech applications be used to promote financial literacy and thereby inclusion? And what role do Fin'Tech organizations play in supporting social progress? The aim of the article is to provide a systematic overview of Fintech's potential to promote digital and financial inclusion on diverse levels.

Keywords: digitalization; FinTech; social progress; financial literacy; financial inclusion; knowledge transfer; innovation.

How to cite: Bähre, H., Buono, G., \& Elss, V. I. (2020). Fintech as a Mean for Digital and Financial Inclusion. In M. W. Staniewski, V. Vasile, \& A. Grigorescu (vol. ed.), Lumen Proceedings: Vol. 14. International Conference Innovative Business Management \& Global Entrepreneurship (IBMAGE 2020) (pp. 205-211). Iasi, Romania: LUMEN Publishing House. https://doi.org/10.18662/lumproc/ibmage2020/15 


\section{Introduction}

Fintech has already evolved to the extent that many sub-sectors of innovation have been named after the specifics of individual services or aspects of the business, so that other industries such as "Regtech, Wealthtech, Proptech, Payments, Trade Finance, Crypto-Currencies, Crowdfunding, Neo- or challenger banks, Robo-Advisors, etc." are growing and specializing

More horizontal technologies are also involved, such as the increasingly popular artificial intelligence and machine learning, large amounts of data, biometrics and the lesser known "block chain" or open banking API (Application Program Interfaces).

As Bill Gates said: "Banking is necessary; banks are not", and this sentence describes very well what is going on in the financial industry as a whole: massive disappearance of traditional jobs, consolidation in banking, robots that advise you how to manage your money and save. Many compare the Fintech revolution to the one that once took place with the arrival of the Internet in the 1990s, but faster, if this is true in 10 years, the world will look very different than today.

To what extent can Fintech applications be used to promote financial literacy and thereby inclusion? And what role do FinTech organizations play in supporting social progress?

The aim of the article is to provide a systematic overview of Fintech's potential to support financial inclusion on diverse levels.

\section{Theoretical Background}

In a paper entitled "Future of Money", published in 2019 by a research group of the SIX Swiss Exchange, a vision of the future, the handling of money and the concept of money is questioned [12].

A reordering of the scenarios drafted in the report according to specific, realistic, and rather short-term trends leads to the following implication (among others according to [6]:

- Money, or whatever means we use to pay or store values, will be purely digital and thus cashless.

- It is likely that different currencies will be used. In addition to the dollars or euros supported by Fiat central banks, decentralized public and private cryptos and other valuable digital assets will also be used (e.g., I can exchange a "share" of my Netflix subscriptions for a certain number of "digital blockbuster points" which in turn give me the right to a coffee; [6]). 
- Smart contract/money for the use and exchange of digital tokens, which may or may not have value depending on the external event, such as a contract of ownership for an apartment, which only becomes real when a certain number of "tokens" are exchanged between two counterparties.

All of this, of course, brings with it an enormous change in infrastructure, what should one do with ATMs? Can they be reused in rural areas to create "micro-local" currencies to encourage recycling? Apart from that, it is tempting. It makes no sense to go further with the imagination, since any technological revolution must also take into account political, legal and real economic as well as social aspects, but it is certain that sooner or later a national banknote will become a piece of an old collection.

On the other side, there are also influences on social structure evident then it comes to Fintech. Fintech has i.e. the potential to catalyse social progress on diverse levels including the supporting of financial literacy and inclusion. In the same manner, Fintech organisations are offering the potential to attract new talents and thereby fostering a diverse workforce. Through technology-enabled innovations it is possible to satisfy specific consumer needs (i.e. also the requirements of elderly people who may not be able to enter a traditional bank i.e. because of social exclusion like physical distances to the next bank). Within Fintech there are some organisations which are promoting social progress on a very concrete level like in the case of Fintech for Good [4]. Fintech for Good is a global not-for-profit movement that aims to support financial literacy on diverse levels but is also dealing with actual topics (i.e. climate responsibility). Another trend within Fintech can be seen in the use of new data sources as a mean for new opportunities (i.e. Apollo Agriculture). Apollo Agriculture [1] is a technology company based in Kenya which supports small-scale farmers to maximize their profit using satellite data collecting and machine-learning processes. The pilot project "Fintech for Impact" [5] aims to foster financial inclusion within the Philippines. "Fintech for Impact" is a cooperation between ING and UNICEF. The starting point can be seen in the search, identification, and investment of up to 100,000 Dollars in Fintech start-ups that are using Fintech solutions in the Philippines or are planning to do so. The program is accompanied by a 1-year mentorship to develop and monitor the social impact of these investments. The reached solutions within the project should be accessible for everyone via an open-source data base. 


\section{Argument of the paper}

On the one hand, the influence of Fintech on the entire financial world is likely to increase soon [12]. On the other hand, as shown above, there are numerous Fintech organizations that explicitly try to increase financial literacy and inclusion through Fintech applications. To what extent can Fintech applications be used to promote financial literacy? And to what extent do such measures also promote financial inclusion? The following literature research aims to offer suggestions how Fintech applications can be instrumentalized to promote financial literacy and thereby financial inclusion.

\section{Fintech as a mean to promote financial literacy and financial inclusion}

Grohmann, Klühs and Menkhoff [7] showed in their study that financial literacy is a relevant precondition then it comes to financial inclusion. Their study included 1,000 adults each country involved with a total of 143 nations. Financial inclusion was measured through four indicators:

- Having a bank account (incl. mobile banking);

- Having a debit card;

- The use of the bank account for saving reasons;

- The use of the debit card within the last 12 months.

Through regression analysis the authors showed over all four indicators that financial literacy had a beneficial effect on financial inclusion even if controlling for the GDP of the nation or the educational attainment at the country level (like participating in secondary and tertiary education). This relation - in case of the indicator "having a bank account" - was even stronger for nations with a very low private credit to GDP ratio.

To recognize this result Fintech applications should be able to influence financial inclusion by promoting financial literacy.

French, McKillop and Stewart (2020) tested for example the effect of smartphone apps ("Money Matters") related to Fintech on the promoting of financial literacy. Their study included four different apps (i.e. loan comparison app, expenditure comparison app, cash calendar app and depth management app) and tested the use of this apps on inhabitants between 16 and 65 years-old of the largest credit union in Northern Island. The authors showed significant improvements in "financial knowledge, understanding and basic skills" but also in "attitudes and motivations" like i.e. to use a digital solution instead of a traditional bank product. The intervention group 
was more likely to keep track on their income and expenditure as well as proved to be more resilient when faced with a financial shock.

\section{Limitations}

Even if the potential of Fintech applications seems to be comprehensive, there are still some aspects to be considered critically:

- In some studies, the operationalization of financial literacy is insufficient (versus Big 3 cf. [9]: 1) numeracy; 2) understanding of inflation; and (3) understanding of risk diversification). If this comprehensive operationalization is not possible, it should be formulated more precisely which subfacet of financial literacy the respective Fintech intervention is aimed at to avoid misunderstandings.

- Fintech applications are not "self-runners". Often, they have to be supplemented by psychological measures to reduce fears and resistance in dealing with modern technologies (especially if the target group includes "digitally excluded persons", e.g. older people).

- Particularly among older people, it is necessary to create transparency in the use of digital products to ensure perceived behavioural control in this new area as well [2].

- the assumed model (i.e. that financial literacy conveys the effect of Fintech applications on financial inclusion assumed by Fintech organizations) requires a causal analysis in the form of a path analysis or a structural equation model.

\section{Counterarguments in relation to the limitations}

Even if limitations exist, the potential of Fintech applications to promote financial literacy and financial inclusion should also be considered. Above all, the following arguments speak in favour of using the corresponding potentials of Fintech applications:

- With regard to the acceptance vs. rejection of new information and communication technologies by e.g. older people, several factors have to be taken into account, but some authors already give suggestions how this can be taken into account [3]: (1) transparency, i.e. the users understand what they can do with a system and what effects their actions have, (2) the reforestation character, i.e. the system can be used intuitively with little learning effort, (3) the feedback, i.e. the system provides 
sufficient and clear feedback which supports the learning process and facilitates the handling and (4) the error correction, i.e. the user does not have to worry about possible mistakes. The system either corrects the respective error itself or shows the user how to correct it.

- Digital financial products offer the potential to enable people who have been financially disconnected to participate in the current financial market (including those with physical disabilities).

\section{Conclusions}

Fintech applications show potential in promoting financial literacy. However, Fintech applications should not be a "general-purpose weapon" for breaking down financial/social barriers. New potentials can be created by following practical recommendations. The mediated connection between Fintech and financial inclusion through financial literacy requires further causal analysis (e.g. in the form of a path analytical model or a structural equation model).

\section{References}

[1] Accion. Checking in with the startup that's revolutionizing Kenyan agriculture: Portfolio engagement: Accion Venture Lab visits Apollo Agriculture; 2018 [cited 2020 September 13] Available from: https://www.accion.org/fintechstartup-revolutionizing-kenyan-agriculture

[2] Ajzen IC, Fishbein MA. The Influence of Attitudes on Behavior. In: Albarracín DO, Johnson BL, Zanna MA, editors. The handbook of attitudes. Mahwah, NJ: Lawrence Erlbaum Associates; 2005; p. 173-221.

[3] Barnard YV, Bradley MI, Hodgson FR, Lloyd AS. Learning to use new technology by older adults: perceived difficulties, experimentation behavior and usability. Computers in Human Behavior. 2013;29:1715-1724.

[4] Fintech for Good. Our origins; 2020 [cited 2020 September 13]. Available from: http://www.fintechforgood.com/index.html

[5] Fintech for Impact. The Programme; 2020 [cited 2020 September 13]. Available from: https://www. fintechforimpact.com/programme

[6] Fraser IA. Five new predictions for the future of money; 2020 [cited 2020 September 13] Available from https://www.raconteur.net/finance/futuremoney-predictions

[7] Grohmann AN, Klühs TH, Menkhoff LU. Does Financial Literacy Improve Financial Inclusion? Cross Country Evidence; 2018 [cited 2020 September 13] 
Available from: https://rationality-and-competition.de/wpcontent/uploads/discussion paper/95.pdf

[8] Leong KE, Sung AN. FinTech (Financial Technology): What is It and How to Use Technologies to Create Business Value in Fintech Way?. International Journal of Innovation, Management and Technology 2018;9(2):74-78.

[9] Lusardi AA. Financial literacy and the need for financial education: evidence and implications. Swiss Journal of Economics and Statistics 2019;155(1):1-8.

[10] Sanicola LE. What is FinTech?. Huffington Post; 2017 [citied 2020 September 13] Available from: https://www.huffpost.com/entry/what-isfintech b 58a20d80e4b0cd37efcfebaa

[11] Schueffel PA. Taming the Beast: A Scientific Definition of Fintech. Journal of Innovation Management 2017;4(4):32-54.

[12] Six. Future of Money; 2019 [cited 2020 September 13]. Available from: https://www.sixgroup.com/dam/download/company/report/whitepapers/six-whitepaperfuture-of-money-full-version-en.pdf 